\title{
ESPECIFICIDADE HOSPEDEIRA DE VARIANTES Bradyrhizobium SPP EM SOJA (CVS PEKING E CLARK), CAUPI E GUANDU ${ }^{(1)}$
}

\author{
Fabíola Gomes de Carvalho( ${ }^{(2)}$, Pedro Alberto Selbach ${ }^{(3)}$ \& Apolino \\ José Nogueira da Silva ${ }^{(4)}$
}

\begin{abstract}
RESUMO
A expansão da cultura da soja evidenciou uma alta especificidade hospedeira, requerendo a pesquisa de novas estirpes que apresentassem capacidade de nodular a soja e bom potencial de competição com a população de rizóbios naturalizada nos solos. $O$ objetivo deste trabalho foi avaliar a especificidade hospedeira de variantes isolados de estirpes de Bradyrhizobium spp quanto à nodulação e eficiência relativa de fixação de $\mathrm{N}_{2}$ atmosférico em soja (cvs peking e clark), caupi e guandu. $O$ experimento foi realizado sob condições controladas em câmara de crescimento por meio de testes de variantes de $B$. japonicum e B. elkanii e suas respectivas estirpes originais quanto à habilidade de nodular soja, caupi e guandu. A colheita foi realizada aos 35 dias, sendo avaliada a nodulação (número, peso dos nódulos secos), produção de matéria seca na parte aérea, eficiência relativa de fixação de $\mathrm{N}_{2}$ atmosférico. Os variantes e estirpes de Bradyrhizobium spp nodularam Glycine max (cultivares BR-16, Clark e Peking), Vigna unguiculata e Cajanus cajan, contudo, apenas para Glycine max a interação rizóbio-leguminosa demonstrou eficiência simbiótica significativa.
\end{abstract}

Termos de indexação: especificidade hospedeira; Bradyrhizobium japonicum; Bradyrhizobium elkanii

\footnotetext{
(1) Parte de Tese de Doutorado do primeiro autor, apresentada ao Departamento de Solos da Universidade Federal do Rio Grande do Sul. Trabalho apresentado no XXXI Congresso Brasileiro de Ciência do Solo, 2007 (Gramado, RS).

(2) Professora do Departamento de Recursos Naturais, CEFET-RN, Av. Senador Salgado Filho, 1559, Tirol, CEP 59015-000, Natal (RN). E-mail: fgcarvalho@cefetrn.br

(3) Professor Adjunto do Departamento de Solos, Universidade Federal do Rio Grande do Sul, Caixa Postal 776, CEP 91501-970 Agronomia - Porto Alegre (RS). E-mail: pselbach@uol.com.br

(4) Professor da Unidade Acadêmica Escola Agrícola de Jundiaí, Universidade Federal do Rio Grande do Norte (UFRN). Caixa Postal 07, CEP 59280-000, Macaíba (RN). E-mail: ajndas@ufrnet.br
} 


\title{
SUMMARY: HOST SPECIFICITY OF BRADYRHIZOBIUM SPP MUTANTS IN SOYBEAN (CULTIVARS PEKING AND CLARK), COWPEA AND PIGEON PEA
}

\begin{abstract}
The expansion of the soybean crop has evidenced a high host specificity, indicating the requirement of new strains with capacity of nodulating soybean and competition capacity with the natural soil rhizobial population. The purpose of this study was to evaluate the host specificity of mutants isolated from Bradyrhizobium spp strains in relation to nodulation and relative $\mathrm{N}_{2}$ fixation effectiveness in soybean (cultivars Peking and Clark), cowpea and pigeon pea. The experiment was carried out under controlled conditions in a growth chamber, where B. japonicum and B. elkanii mutants and the respective original strains were tested for their nodulation ability on soybean, cowpea and pigeon pea. The crop was harvested 35 days after planting and the nodulation (number, dry nodule weight), shoot dry matter production and relative $\mathrm{N}_{2}$ fixation effectiveness were evaluated. The mutants and strains of Bradyrhizobium spp nodulate Glycine max (cultivars BR-16, Clark and Peking), Vigna unguiculata and Cajanus cajan, however the interaction rhizobia-leguminous demonstrated significant symbiotic effectiveness for Glycine max only.
\end{abstract}

Index terms: host specificity; Bradyrhizobium japonicum; Bradyrhizobium elkanii.

\section{INTRODUÇÃO}

A especificidade hospedeira representa a habilidade de uma estirpe de rizóbio em provocar a nodulação e, ou, fixar $\mathrm{N}_{2}$ quando associada a cultivares ou espécies do hospedeiro específico, sendo por isso uma importante característica a ser considerada em programas de seleção de novas estirpes (Peres et al., 1993).

O mecanismo de reconhecimento na associação rizóbio/leguminosa obedece a um complexo conjunto de informações genéticas entre a planta e bactéria (Perret et al., 2000). De acordo com Cardoso \& Freitas (1992), os rizóbios seriam, na realidade, parasitas extremamente refinados, que por meio de uma evolução conjunta com o hospedeiro transformaram o processo parasitário em simbiótico, causando muito mais benefícios do que danos. Tal afirmação baseiase no fato de que vários genes necessários para parasitismo e amplitude de hospedeiros em Rhizobium são similares àqueles presentes em Agrobacterium, uma bactéria patogênica em plantas, também classificada na família Rhizobiacea (Perret et al., 2000).

$\mathrm{Na}$ década de 70, com a expansão da cultura da soja na região do Cerrado brasileiro, o cultivar de soja IAC-2 passou a ser recomendado para o plantio nessa área. Porém, a alta especificidade hospedeira desse cultivar dificultou o estabelecimento de uma simbiose eficiente. Assim, foram pesquisadas novas estirpes que apresentassem capacidade de nodular o cultivar de soja IAC-2 e bom potencial de competição com a população de rizóbios naturalizada nos solos. Foram selecionadas duas variantes: a CPAC 7 (SEMIA 5080), obtida após subcultivos da estirpe SEMIA 586 (CB 1809), e a variante CPAC-15 (SEMIA 5079) isolada de campo de Cerrado, considerada uma mutante natural da SEMIA 566 (BR 40) (Boddey, 1995).
De acordo com Stacey et al. (1994), a especificidade hospedeira em B. japonicum estaria relacionada, pelo menos em parte, com a presença do radical 2-Ometilfucose na estrutura básica do oligossacarídeo lipoquitínico (LCO) nesta espécie. Ainda que se tenham informações sobre a influência das substituições no fator Nod, nenhuma correlação exata pode ser feita entre o tipo de LCO produzido pelo rizóbio e a planta que ele nodula (Perret et al., 2000). Por exemplo: Rhizobium etli e $R$. loti têm o mesmo fator Nod, mas nodulam com espécies distintas de feijoeiro (Cardenas et al., 1995), o mesmo sendo observado com dois biovares de $R$. leguminosarum que embora tenham o mesmo fator Nod, também nodulam com espécies diferentes (Orgambide et al., 1995). Outro exemplo interessante que pode ser citado é a nodulação de feijoeiro com $R$. tropici e $R$. etlli, porém nesse caso existem diferentes tipos de fator Nod (Poupot et al., 1993). Contudo, cada vez mais se acredita que tal especificidade esteja relacionada com um conjunto de fatores e não com um único fator (Vargas \& Hungria, 1997).

As proteínas NodD apresentam comprovada habilidade para reconhecer diferentes indutores; contudo, tais proteínas não são as únicas determinantes da especificidade hospedeira que uma estirpe revela, uma vez que, em várias etapas do processo de infecção, são requisitados componentes adicionais da parede celular (EPS e LPS) e, em alguns casos, a secreção de proteínas específicas também se faz necessária para que ocorra um completo processo de infecção e formação dos nódulos (Denarié et al., 1996 citado por Hadri et al., 1998).

A especificidade entre parceiros compatíveis teoricamente minimizaria as chances de infecção por patógenos e formação de associações inefetivas que seriam prejudiciais a ambos os simbiontes (Perret et 
al., 2000). Contudo, Yuen et al. (1995) citados por Vargas \& Hungria (1997) relataram que moléculas liberadas por não-hospedeiros também são capazes de induzir os genes nod, por exemplo, duas xantonas presentes em Haploclathra spp induziram genes de nodulação em B. japonicum. Porém, conforme afirmado por Vargas \& Hungria (1997), atualmente, só existem especulações sobre o significado ecológico da indução dos genes de nodulação por não-hospedeiros.

Assim, baseado nos diversos estudos envolvidos com a especificidade hospedeira de rizóbios e bradirrizóbios, torna-se evidente que um alto grau de especificidade em relação ao hospedeiro parece ser a exceção e não a regra (Neves \& Rumjanek, 1996). A escolha de estirpes que apresentem baixa especificidade é recomendável, uma vez que a variabilidade genética entre os cultivares de leguminosas tem sido apontada como uma das causas que afetam a eficiência fixadora de $\mathrm{N}_{2}$ das estirpes durante a simbiose (Peres, 1979).

Este trabalho foi realizado com o objetivo de avaliar a especificidade hospedeira de variantes isolados de estirpes de Bradyrhizobium spp quanto à nodulação e eficiência relativa de fixação de $\mathrm{N}_{2}$ atmosférico em soja (cvs peking e clark), caupi e guandu.

\section{MATERIAL E MÉTODOS}

O experimento realizado sob condições controladas em câmara de crescimento testou variantes de estirpes de $B$. japonicum e $B$. elkanii e suas respectivas estirpes originais quanto à habilidade de nodular os seguintes hospedeiros: cultivares de soja Clark e Peking, Vigna unguiculata (cultivar IPA 206) e Cajanus cajan.

As estirpes de Bradyrhizobium japonicum (SEMIA 5079 e SEMIA 5080) e Bradyrhizobium elkanii (SEMIA 587 e SEMIA 5019) utilizadas no experimento foram cedidas pelo Centro de Recursos Microbiológicos (MIRCEN) - Fundação de Pesquisa Agropecuária do Rio Grande do Sul (FEPAGRO).

A seleção dos variantes de Bradyrhizobium spp foi baseada em propriedades relacionadas com a eficiência simbiótica, a partir de um experimento realizado com o cultivar de soja BR-16 inoculada com as estirpes de B. elkanii) e B. japonicum. (Carvalho et al., 2005).

A câmara de crescimento foi mantida em temperatura de $26^{\circ} \mathrm{C}$ e regime de luminosidade de $13 \mathrm{~h} / 11 \mathrm{~h}$ (dia/noite). O substrato utilizado foi composto por uma mistura areia e carvão vegetal moído na proporção de $3: 1$ autoclavado por $2 \mathrm{~h}$, a $120{ }^{\circ} \mathrm{C}$ e 1 atmosfera de pressão.

Os tratamentos em triplicata receberam solução nutritiva de Norris isenta de $\mathrm{N}$, esterilizada e com $\mathrm{pH}$ ajustado para 6,0. Além dos tratamentos inoculados, havia tratamentos-controle sem inoculação: testemunha sem adição de $\mathrm{N}$ e testemunha nitrogenada: $2,14 \mathrm{~g}$ vaso de $\mathrm{N}$ na forma de $\mathrm{NH}_{4} \mathrm{NO}_{3}$. A solução de $\mathrm{NH}_{4} \mathrm{NO}_{3}$ foi parcelada 15 e 30 dias após o plantio.

A colheita foi realizada aos 35 dias, sendo os nódulos classificados quanto ao número, bem como determinados o peso dos nódulos secos e a produção de matéria seca na parte aérea.

O índice de efetividade simbiótica (Efra) dos variantes foi calculado por meio da equação 1 , conforme descrito por Brockwell et al. (1966) citado por Sá (2001). Com base nos Efra, foram selecionados os variantes mais promissores utilizados nas próximas etapas do trabalho.

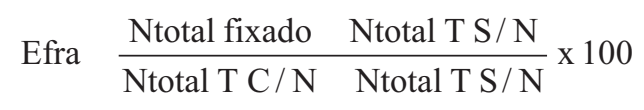

em que: Ntotal fixado = Nitrogênio total do tratamento Ntotal $\mathrm{T}$ S/N = Nitrogênio total da testemunha sem nitrogênio

Ntotal $\mathrm{T} \mathrm{C} / \mathrm{N}=$ Nitrogênio total $\mathrm{da}$ testemunha nitrogenada

Os resultados obtidos foram analisados no programa estatístico SANEST e submetidos à análise de variância com teste de $\mathrm{F}$, utilizando-se o Teste de Tukey a $5 \%$ para comparação entre médias de tratamentos.

\section{RESULTADOS E DISCUSSÃO}

Para os valores médios do número de nódulos produzidos no cultivar Clark, não houve diferença significativa entre os tratamentos inoculados com variantes e estirpes originais (Quadro 1). Os tratamentos inoculados com os variantes $1 \mathrm{~B}$ e $1 \mathrm{C}$ apresentaram maiores valores de massa nodular do que os tratamentos inoculados com as suas estirpes originais SEMIA 5080 (B) e SEMIA 587 (C).

Os melhores rendimentos médios de matéria seca foram obtidos pelos tratamentos inoculados com a estirpe original SEMIA 587 e os seus variantes, apresentando os tratamentos inoculados com os variantes $3 \mathrm{C}$ e $6 \mathrm{C}$ médias para o acúmulo de matéria seca superiores aos demais tratamentos (Quadro 1).

Para o cultivar de soja Peking, observou-se um maior número de nódulos nos tratamentos inoculados com as variantes de $B$. japonicum em relação à estirpe SEMIA 5079 (Quadro 1). Diferenças somente foram observadas entre o tratamento inoculado com a estirpe SEMIA 5032 e os tratamentos representados pelo variante $3 \mathrm{C}$ e as estirpes originais SEMIA 5080 e SEMIA 5079. Não houve diferença estatística entre os valores de massa de nódulos secos entre os tratamentos inoculados. 
Quadro 1. Avaliação da nodulação (número e massa de nódulos secos) e da produção de matéria seca da parte aérea de soja cultivares Clark e Peking, inoculadas com estirpes e variantes de Bradyrhizobium spp, 35 dias após o plantio

\begin{tabular}{|c|c|c|c|c|c|c|}
\hline \multirow{3}{*}{ Tratamento } & \multicolumn{3}{|c|}{ Cultivar Clark } & \multicolumn{3}{|c|}{ Cultivar Peking } \\
\hline & \multicolumn{2}{|c|}{ Nodulação } & \multirow{2}{*}{$\begin{array}{l}\text { Parte Aérea } \\
\text { Matéria seca }\end{array}$} & \multicolumn{2}{|c|}{ Nodulação } & \multirow{2}{*}{$\begin{array}{l}\text { Parte Aérea } \\
\text { Matéria seca }\end{array}$} \\
\hline & Nódulos & $\begin{array}{l}\text { Massa de nódulos } \\
\text { secos }\end{array}$ & & Nódulos & $\begin{array}{l}\text { Massa de nódulos } \\
\text { secos }\end{array}$ & \\
\hline & $\mathrm{N}^{\circ}$ vaso $^{-1}$ * & mg vaso $^{-1}$ & g vaso-1 & $\mathbf{N}^{\circ}$ vaso $^{-1}$ * & mg vaso-1 $^{-1}$ & g vaso-1 \\
\hline SEMIA 5079 (A) & $63,3 \mathrm{a}$ & $135,00 \mathrm{ab}$ & $1,84 \mathrm{~cd}$ & $7,2 \mathrm{c}$ & $46,30 \mathrm{a}$ & $0,82 \mathrm{gh}$ \\
\hline $1 \mathrm{~A}$ & $60,3 \mathrm{a}$ & $118,76 \mathrm{abc}$ & $1,57 \mathrm{cde}$ & $32,1 \mathrm{ab}$ & $53,93 \mathrm{a}$ & $1,04 \mathrm{fg}$ \\
\hline $2 \mathrm{~A}$ & $42,9 \mathrm{ab}$ & $132,66 \mathrm{ab}$ & $1,50 \mathrm{cdef}$ & $38,6 \mathrm{ab}$ & $52,63 \mathrm{a}$ & $0,94 \mathrm{~g}$ \\
\hline $3 \mathrm{~A}$ & $52,9 \mathrm{ab}$ & $118,56 \mathrm{abc}$ & $1,18 \mathrm{efg}$ & $36,9 \mathrm{ab}$ & $50,03 \mathrm{a}$ & $0,82 \mathrm{gh}$ \\
\hline SEMIA 5080 (B) & $45,6 \mathrm{ab}$ & $42,00 \mathrm{~d}$ & $1,07 \mathrm{fg}$ & $28,4 \mathrm{bc}$ & $52,47 \mathrm{a}$ & 1,30 defg \\
\hline $1 \mathrm{~B}$ & $60,0 \mathrm{ab}$ & $151,00 \mathrm{a}$ & $1,69 \mathrm{~cd}$ & $38,3 \mathrm{ab}$ & $55,33 \mathrm{a}$ & $1,59 \mathrm{cde}$ \\
\hline $3 \mathrm{~B}$ & $44,3 \mathrm{ab}$ & 70,66 bcd & $1,17 \mathrm{efg}$ & $36,2 \mathrm{ab}$ & $95,20 \mathrm{a}$ & $1,53 \mathrm{cde}$ \\
\hline $4 \mathrm{~B}$ & $47,7 \mathrm{ab}$ & 86,67 abcd & $1,41 \mathrm{def}$ & $37,6 \mathrm{ab}$ & $79,53 \mathrm{a}$ & $1,61 \mathrm{cde}$ \\
\hline $\begin{array}{l}\text { SEMIA } \\
587(\mathrm{C})\end{array}$ & $42,2 \mathrm{ab}$ & $39,66 \mathrm{~d}$ & $1,88 \mathrm{c}$ & $56,9 \mathrm{ab}$ & $102,27 \mathrm{a}$ & $1,88 \mathrm{bc}$ \\
\hline $1 \mathrm{C}$ & $42,3 \mathrm{ab}$ & $127,00 \mathrm{abc}$ & $1,94 \mathrm{bc}$ & $50,1 \mathrm{ab}$ & $94,27 \mathrm{a}$ & $1,86 \mathrm{bc}$ \\
\hline $3 \mathrm{C}$ & $49,8 \mathrm{ab}$ & $79,66 \mathrm{bcd}$ & $2,38 \mathrm{ab}$ & $28,7 \mathrm{bc}$ & $52,93 \mathrm{a}$ & $2,13 \mathrm{ab}$ \\
\hline $6 \mathrm{C}$ & $45,8 \mathrm{ab}$ & $73,33 \mathrm{bcd}$ & $2,39 \mathrm{a}$ & $41,0 \mathrm{ab}$ & $76,93 \mathrm{a}$ & $2,55 \mathrm{a}$ \\
\hline SEMIA 5019 (D) & $26,5 \mathrm{~b}$ & $85,00 \mathrm{abcd}$ & 1,60 cde & $44,7 \mathrm{ab}$ & $81,00 \mathrm{a}$ & $2,51 \mathrm{a}$ \\
\hline $1 \mathrm{D}$ & $41,0 \mathrm{ab}$ & $126,66 \mathrm{abc}$ & $1,52 \mathrm{cdef}$ & $38,1 \mathrm{ab}$ & $58,20 \mathrm{a}$ & $1,72 \mathrm{bcd}$ \\
\hline $2 \mathrm{D}$ & $30,4 \mathrm{~b}$ & 94,66 abcd & $1,52 \mathrm{cdef}$ & $36,8 \mathrm{ab}$ & $66,60 \mathrm{a}$ & 1,15 efg \\
\hline SEMIA 5087 & $51,7 \mathrm{ab}$ & $61,33 \mathrm{~cd}$ & 1,17 efg & $35,8 \mathrm{ab}$ & $68,33 \mathrm{a}$ & $1,47 \mathrm{cdef}$ \\
\hline SEMIA 5032 & $27,6 \mathrm{~b}$ & $33,00 \mathrm{~d}$ & $1,85 \mathrm{c}$ & $72,3 \mathrm{a}$ & $43,66 \mathrm{a}$ & $1,22 \mathrm{efg}$ \\
\hline TA & - & - & $0,90 \mathrm{~g}$ & - & - & $0,47 \mathrm{~h}$ \\
\hline $\mathrm{TN}$ & - & - & $1,41 \mathrm{def}$ & - & - & $0,94 \mathrm{~g}$ \\
\hline CV (\%) & 18,4 & 20,1 & 15,9 & 17,8 & 20,5 & 15,7 \\
\hline
\end{tabular}

* Dados transformados por $\sqrt{\mathrm{x}+1}$. Médias seguidas da mesma letra na coluna não diferem significativamente pelo teste de Tukey $5 \%$. TA = Testemunha absoluta; $\mathrm{TN}=$ Testemunha nitrogenada; $\mathrm{CV}=$ Coeficiente de variação.

A média de produção de matéria seca do tratamentocontrole com adição de $\mathrm{N}$ foi similar ou inferior aos tratamentos inoculados no cultivar de soja Peking (Quadro 1). Os melhores rendimentos de matéria seca foram obtidos quando a estirpe de B. elkanii SEMIA 5019 ou os variantes $3 \mathrm{C}$ e $6 \mathrm{C}$ foram inoculados neste cultivar.

As médias dos índices de eficiência relativa obtidas nos cultivares de soja Clark e Peking encontram-se nas figuras 1 e 2 .

Os índices de eficiência relativa obtidos por estirpes de $B$. japonicum e B. elkanii, quando inoculadas no cultivar de soja Clark, variaram de 34 a $292 \%$ (Figura 1). Em geral, os tratamentos inoculados com estirpes originais e variantes apresentaram comportamento bem heterogêneo, tendo as estirpes SEMIA 5079 e 5019 apresentado maior eficiência relativa em relação aos seus variantes, enquanto as estirpes SEMIA 5080 e 587 foram menos eficientes, quando comparadas aos seus variantes. Quanto às estirpes SEMIA 5032 e
SEMIA 5087, observou-se que a inoculação da estirpe SEMIA 5032 (B. japonicum) apresentou maior eficiência do que a estirpe SEMIA 5087 (B. elkanii).

No cultivar de soja Peking e no cultivar Clark, constatou-se um padrão heterogêneo quanto ao índice de eficiência relativa observado entre estirpes originais e variantes. Contudo, nesse cultivar de soja, os índices de eficiência relativa foram bem mais elevados e variaram de 79 a $472 \%$ (Figura 2 ).

O comportamento das estirpes SEMIA 5032 e SEMIA 5087 no cultivar Peking foi inverso ao observado no cultivar Clark, constatou-se maior eficiência da estirpe SEMIA 5087 quanto ao índice de eficiência relativa (Figuras 1 e 2).

Nas condições desse experimento, foi observado que, em geral, a eficiência simbiótica das estirpes brasileiras das espécies $B$. japonicum, B. elkanii e estirpes-padrão dessas espécies (SEMIA 5032 e SEMIA 5087) foi dependente do cultivar de soja utilizada 
(Figuras 1 e 2). Vidor et al. (1972) citados por Carvalho et al. (2005) e Hungria \& Bohrer (2000), também observaram um efeito acentuado da interação entre cultivares e estirpes de Bradyrhizobium spp usados em inoculantes no Brasil.

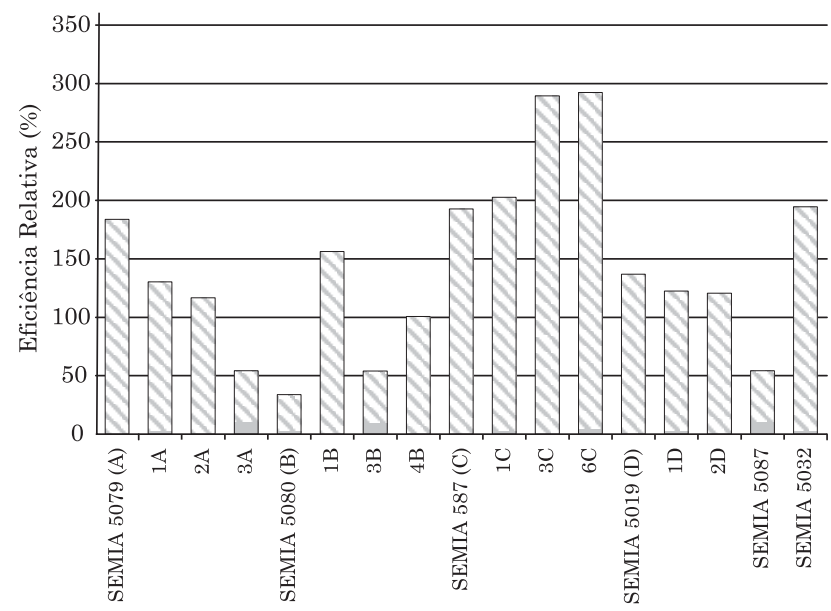

Figura 1. Índices de eficiência relativa dos tratamentos inoculados com estirpes e variantes de B. japonicum e B. elkanii em relação à produção de matéria seca de soja cultivar Clark, 35 dias após o plantio.

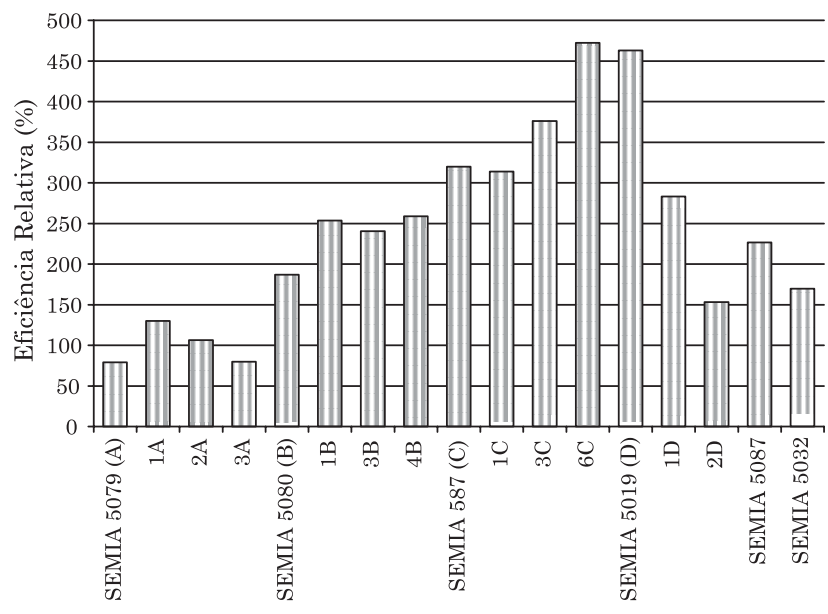

Figura 2. Índices de eficiência relativa dos tratamentos inoculados com estirpes e variantes de B. japonicum e B. elkanii em relação à produção de matéria seca de soja cultivar Peking, 35 dias após o plantio.

Em B. japonicum, a estirpe SEMIA 5079 e o variante 2A, assim como a estirpe SEMIA 5032, apresentaram melhor eficiência quando associadas ao cultivar de soja Clark, enquanto a estirpe SEMIA 5080 e seus variantes apresentaram maior eficiência quando associadas ao cultivar de soja Peking. No grupo de $B$. elkanii (SEMIA 5087, SEMIA 587, SEMIA 5019 e seus variantes), o comportamento geral nesta espécie foi de uma melhor associação com o cultivar de soja Peking (Figuras 1 e 2). Minamisawa et al. (1997) observaram que a ocupação nodular nas espécies $B$. japonicum e $B$. elkanii foi determinada exclusivamente pelo hospedeiro, uma vez que $B$. japonicum nodulou preferencialmente com vários cultivares de Glycine max, enquanto B. elkanii foi mais competitivo com o cultivar primitivo de soja Peking e com Macroptilium atropurpureum.

O cultivar Peking é um cultivar primitivo de soja que apresenta sementes com coloração escura, graças à presença de antocianinas, sendo provável que, de forma semelhante ao que acontece em cultivares de feijão preto, onde a presença desses pigmentos tem sido relatada como o mais ativo indutor dos genes nod (Hungria et al., 1991; Hungria \& Phillips, 1993), também no cultivar de soja Peking a presença de antocianinas poderia ter sido responsável por melhor indução dos genes de nodulação nas diferentes estirpes e variantes de bradirrizóbios estudadas, resultando na maior eficiência relativa observada neste cultivar. Contudo, admitindo que os flavonóides sintetizados nos cultivares de soja Clark e Peking tenham a mesma composição, é provável que a quantidade desses compostos possa ter interferido no reconhecimento entre leguminosa e bactéria, influenciando, conseqüentemente, os índices de eficiência observada para a maioria das estirpes e variantes testados, visto que a nodulação da soja, assim como a do feijoeiro, pode ser limitada pela quantidade de indutores dos genes nod, conforme observado por Vargas \& Hungria (1997) e Pueppke et al. (1998).

Os resultados de nodulação e produção de matéria seca da parte aérea em caupi e guandu são apresentados no quadro 2. Observa-se que, em geral, os tratamentos inoculados com os variantes originados das estirpes SEMIA 5079 e SEMIA 5080 apresentaram melhor desempenho quanto ao número de nódulos, massa nodular e produção de matéria seca que as suas respectivas estirpes originais, enquanto as estirpes originais SEMIA 587 e SEMIA 5019 apresentaram maior número de nódulos em relação aos seus variantes. Os tratamentos inoculados com as estirpes SEMIA 5032 e SEMIA 5087 seguiram a tendência geral observada para as estirpes B. elkanii e B. japonicum, nos quais a maior nodulação foi observada quando a estirpe SEMIA 5087 foi inoculada (B. elkanii).

Em caupi, os tratamentos inoculados apresentaram produção de matéria seca inferior ou equivalente à testemunha nitrogenada. Contudo, outros tratamentos revelam desempenho menor que o observado na testemunha absoluta (Quadro 2). Nas infecções envolvendo o gênero Bradyrhizobium, tem sido relatado que espécies promíscuas como $V$. unguiculata, em geral, não respondem à inoculação sob condições de campo (Vargas \& Suhet, 1981). Entretanto, sob determinadas circunstâncias, $V$. unguiculata pode responder favoravelmente à inoculação, dependendo do tipo de solo, número, efetividade e grau de especificidade das estirpes nativas, conforme constatado por Bushby (1984). 
Quadro 2. Avaliação da nodulação (número e massa de nódulos secos) e da produção de matéria seca da parte aérea de caupi cultivar IPA 206, e de guandu, inoculados com estirpes e variantes de Bradyrhizobium spp, 35 dias após o plantio

\begin{tabular}{|c|c|c|c|c|c|c|}
\hline \multirow{3}{*}{ Tratamento } & \multicolumn{3}{|c|}{ Caupi } & \multicolumn{3}{|c|}{ Guandu } \\
\hline & \multicolumn{2}{|c|}{ Nodulação } & \multirow{2}{*}{$\begin{array}{l}\text { Parte Aérea } \\
\text { Matéria seca }\end{array}$} & \multicolumn{2}{|c|}{ Nodulação } & \multirow{2}{*}{$\begin{array}{l}\text { Parte Aérea } \\
\text { Matéria seca }\end{array}$} \\
\hline & Nódulos & $\begin{array}{c}\text { Massa de } \\
\text { nódulos secos }\end{array}$ & & Nódulos & $\begin{array}{c}\text { Massa de } \\
\text { nódulos secos }\end{array}$ & \\
\hline & $\mathbf{N}^{\circ}$ vaso $^{-1}$ * & mg vaso-1 & g vaso-1 & $\mathrm{N}^{\circ}$ vaso $^{-1}$ * & mg vaso-1 & g vaso-1 \\
\hline SEMIA 5079 (A) & $11,0 \mathrm{e}$ & $7,00 \mathrm{~d}$ & $0,64 \mathrm{~h}$ & $7,5 \mathrm{~g}$ & $4,00 \mathrm{de}$ & $0,33 \mathrm{~cd}$ \\
\hline $1 \mathrm{~A}$ & 24,9 bcde & $16,00 \mathrm{~d}$ & $1,45 \mathrm{a}$ & 33,2 bcde & 9,43 bcde & $0,38 \mathrm{bcd}$ \\
\hline $2 \mathrm{~A}$ & 26,7 bcde & $8,73 \mathrm{~d}$ & $0,90 \mathrm{fgh}$ & $65,4 \mathrm{ab}$ & $19,00 \mathrm{a}$ & $0,47 \mathrm{bc}$ \\
\hline $3 \mathrm{~A}$ & $33,5 \mathrm{abc}$ & $17,66 \mathrm{~d}$ & $0,70 \mathrm{gh}$ & 31,8 bcdef & $12,33 \mathrm{abcd}$ & $0,40 \mathrm{bcd}$ \\
\hline SEMIA 5080 (B) & $12,9 \mathrm{de}$ & $15,96 \mathrm{~d}$ & $0,90 \mathrm{fgh}$ & $71,1 \mathrm{a}$ & $16,30 \mathrm{ab}$ & $0,48 \mathrm{~b}$ \\
\hline 1B & 21,3 cde & $45,66 \mathrm{abc}$ & 1,18 bcde & 30,8 bcdef & $13,07 \mathrm{abc}$ & $0,49 \mathrm{~b}$ \\
\hline 3B & $21,4 \mathrm{cde}$ & $46,53 \mathrm{abc}$ & $1,35 \mathrm{abc}$ & $47,6 \mathrm{abc}$ & 8,33 bcde & $0,45 \mathrm{bc}$ \\
\hline $4 \mathrm{~B}$ & 14,8 cde & $24,33 \mathrm{bcd}$ & 1,26 abcd & 45,6 abcd & 10,63 abcde & $0,48 \mathrm{~b}$ \\
\hline SEMIA 587 (C) & $32,3 \mathrm{abc}$ & $20,50 \mathrm{~cd}$ & 1,19 abcd & 26,1 cdefg & 6,87 cde & $0,18 \mathrm{e}$ \\
\hline $1 \mathrm{C}$ & 22,5 cde & $14,50 \mathrm{~d}$ & $0,72 \mathrm{gh}$ & 38,7 abcd & 10,13 bcde & $0,49 \mathrm{~b}$ \\
\hline $3 \mathrm{C}$ & $29,0 \mathrm{bcd}$ & $18,96 \mathrm{~cd}$ & $1,43 \mathrm{ab}$ & $9,5 \mathrm{fg}$ & $2,53 \mathrm{e}$ & $0,35 \mathrm{bcd}$ \\
\hline $6 \mathrm{C}$ & 23,0 cde & $14,90 \mathrm{~d}$ & 1,12 cdef & 35,8 abcd & 9,40 bcde & $0,36 \mathrm{bcd}$ \\
\hline SEMIA 5019 (D) & $57,8 \mathrm{a}$ & $12,20 \mathrm{~d}$ & 1,26 abcd & $11,4 \mathrm{efg}$ & $3,03 \mathrm{e}$ & $0,38 \mathrm{bcd}$ \\
\hline $1 \mathrm{D}$ & 28,2 bcde & 59,66 a & $0,74 \mathrm{gh}$ & $18,2 \mathrm{defg}$ & 4,80 cde & $0,37 \mathrm{bcd}$ \\
\hline $2 \mathrm{D}$ & $10,8 \mathrm{e}$ & $23,10 \mathrm{bcd}$ & $0,85 \mathrm{fgh}$ & 30,9 bcdef & 8,13 bcde & $0,47 \mathrm{bc}$ \\
\hline SEMIA 5087 & $49,0 \mathrm{ab}$ & $21,60 \mathrm{~cd}$ & $1,03 \mathrm{def}$ & $45,1 \mathrm{abcd}$ & $13,13 \mathrm{abc}$ & $0,43 \mathrm{bc}$ \\
\hline SEMIA 5032 & 27,6 bcde & $49,80 \mathrm{ab}$ & $0,90 \mathrm{fgh}$ & 33,3 bcde & 6,23 cde & $0,42 \mathrm{bcd}$ \\
\hline $\mathrm{TA}$ & - & - & 0,92 efg & - & - & $0,28 \mathrm{de}$ \\
\hline $\mathrm{TN}$ & - & - & $1,38 \mathrm{abc}$ & - & - & $0,64 \mathrm{a}$ \\
\hline CV (\%) & 16,8 & 18,7 & 18,3 & 19,2 & 21,3 & 15,2 \\
\hline
\end{tabular}

* Dados transformados por $\sqrt{\mathrm{x}+1}$. Médias seguidas da mesma letra na coluna não diferem significativamente pelo teste de Tukey $5 \%$ TA = Testemunha absoluta; $\mathrm{TN}=$ Testemunha nitrogenada; $\mathrm{CV}=$ Coeficiente de variação.

Com relação ao guandu, observou-se que, em geral, os tratamentos inoculados com variantes dos grupos de B. japonicum e B. elkanii levaram à maior formação de nódulos e apresentaram valores de massa nodular e produção de matéria seca superiores ou equivalentes aos obtidos pelas suas estirpes originais. Dentre os tratamentos inoculados com as estirpes SEMIA 5087 e SEMIA 5032, não houve diferenças quanto às propriedades analisadas (Quadro 2), apesar de se observar melhor desempenho da estirpe SEMIA 5087 quanto ao número de nódulos formados, massa nodular e produção de matéria seca.

Em guandu, os tratamentos inoculados apresentaram produção de matéria seca inferior à da testemunha nitrogenada, também existindo tratamentos inoculados em que o desempenho foi equivalente ou até menor do que o observado na testemunha absoluta (Quadro 2).

As médias dos índices de eficiência relativa obtida em caupi estão apresentadas na figura 3. Observa-se que, entre variantes e estirpes de $B$. japonicum e $B$. elkanii inoculadas, $53 \%$ (9/17) apresentaram índices de eficiência negativos variáveis de -4 a $-126 \%$ (Figura 3 ), sendo a maior ocorrência dos índices negativos observada na espécie B. japonicum, onde $100 \%$ das estirpes originais e a estirpe.SEMIA 5032 apresentaram índices negativos. Em B. elkanii, índices de eficiência negativos foram observados apenas quando foram inoculados os variantes $1 \mathrm{C}, 1 \mathrm{D}$ e $2 \mathrm{D}$ (Figura 3).

Os índices de eficiência relativa para o guandu, em geral, ficaram abaixo de $60 \%$, sendo ainda observado que o tratamento inoculado com a estirpe SEMIA 587 foi o único tratamento que apresentou índice de eficiência negativo (-28\%) (Figura 4). Na inoculação de estirpes e variantes de B. japonicum, incluindo a estirpe SEMIA 5032, os índices variaram de 13 a $58 \%$, observando-se que a estirpe SEMIA 5079 e seus variantes apresentaram índices de eficiência menores que os da estirpe SEMIA 5080 e seus variantes. Os índices de eficiência variaram de -28 a 
59 \% quando estirpes e variantes de B. elkanii foram inoculados. Em guandu, a tendência observada entre todos os tratamentos inoculados foi a de um melhor desempenho dos variantes em relação às suas estirpes originais.

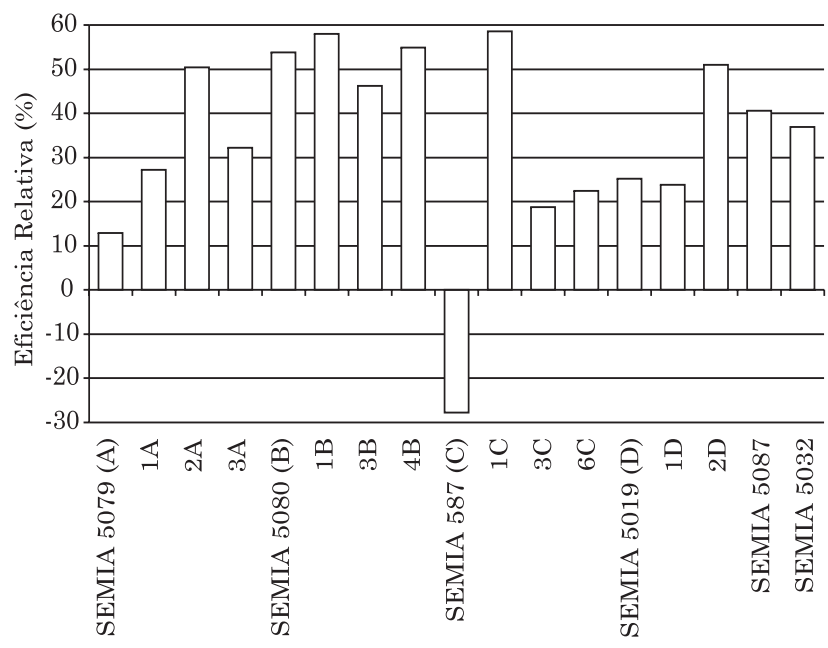

Figura 3. Índices de eficiência relativa dos tratamentos inoculados com estirpes e variantes de $B$. japonicum e B. elkanii em relação à produção de matéria seca de caupi cultivar IPA 206, 35 dias após o plantio.

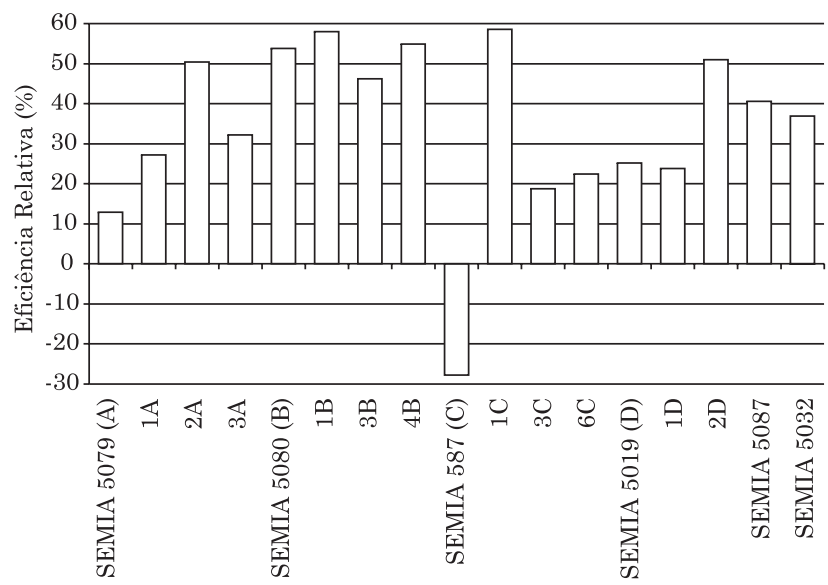

Figura 4. Índices de eficiência relativa dos tratamentos inoculados com estirpes e variantes de B. japonicum e B. elkanii em relação à produção de matéria seca de guandu, 35 dias após o plantio.

De acordo com Singleton et al. (1992), nem todas as estirpes que nodulam determinado grupo de leguminosas são eficientes na fixação de $\mathrm{N}_{2}$ com todas as espécies, conforme também constatado no presente estudo, quando estirpes e variantes de $B$. japonicum e B. elkanii foram inoculadas em soja, caupi e guandu.
Os índices negativos de eficiência observados em caupi e guandu (Figuras 3 e 4) indicaram a ausência de fixação de $\mathrm{N}_{2}$ e diminuição da produção de matéria seca da parte aérea e, para a maioria dos tratamentos inoculados, não houve diferença estatística em relação à testemunha absoluta (Quadro 2). Assim, a partir dos resultados de eficiência relativa obtida por caupi e guandu, observou-se que ambas as leguminosas não responderam à inoculação com rizóbios nãohomólogos (rizóbios isolados de seu próprio hospedeiro) e, na ausência de uma simbiose efetiva, os bradirrizóbios comportaram-se como simples parasitas radiculares.

\section{CONCLUSÃO}

1. Todos os variantes e estirpes de Bradyrhizobium spp nodularam Glycine max (cultivares BR-16, Clark e Peking), Vigna unguiculata e Cajanus cajan, contudo apenas para Glycine max a interação rizóbioleguminosa demonstrou eficiência significativa.

\section{AGRADECIMENTOS}

Os autores agradecem à Universidade Federal do Rio Grande do Sul (UFRGS) pelo financiamento do projeto, e à Coordenação de Aperfeiçoamento de Pessoal de Nível Superior (CAPES), pela concessão das bolsas de estudo.

\section{LITERATURA CITADA}

BODDEY, L.H. Determinação das características das espécies Bradyrhizobium japonicum e Bradyrhizobium elkanii nas estirpes brasileiras noduladoras de soja. Londrina, Universidade Estadual de Londrina, 1995. 130p. (Tese de Mestrado)

BUSHBY, H.V.A. Colonization of rhizospheres and nodulation of two Vigna species by rhizobia inoculated onto seed: Influence of soil. Soil Biol. Biochem., 16:635-641, 1984.

CARDENAS, L.; DOMINGUEZ, J.; QUINTO, C.; LOPEZ-LARA, I.M.; LUGTENBERG, B.J.J.; SPAINK, H.P.; RADEMAKER, G.J.; HAVERKAMP, J. \& THOMAS-OATES, J.E. Isolation, chemical structure and biological activity of the lipo-chitin oligosaccharide nodulation signals form Rhizobium etli. Plant Molec. Biol., 29:453-464, 1995.

CARDOSO, E.J.B.N. \& FREITAS, S.S. A rizosfera. In: CARDOSO, E.J.B.N.; TSAI, S.M. \& NEVES, M.C.P., eds. Microbiologia do solo. Campinas, Sociedade Brasileira de Ciência do Solo, 1992. p.41-57.

CARVALHO, F.G.; SELBACH, P.A. \& BIZARRO, M.J. Eficiência e competitividade de variantes espontâneos isolados de estirpes de Bradyrhizobium spp recomendadas para a cultura da soja (Glycine Max). R. Bras. Ci. Solo, 29:883-891, 2005. 
HADRI, A.Z.; SPAINK, H.P.; BISSELING, T. \& BREWIN, N.J. Diversity of root nodulation and rhizobial infection process. In: SPAINK, H.P.; KONDOROSI, A. \& HOOYKAAS, P.J.J., eds. The Rhizobiaceae: Molecular biology of model plant-associated bacteria. Dordrecht, Kluver Academic Publisher, 1998. p.348. 349 .

HUNGRIA, M. \& BOHRER, T.R.J. Variability of nodulation and dinitrogen fixation capacity among soybean cultivars. Biol. Fert. Soils, 31:45-52, 2000.

HUNGRIA, M. \& PHILLIPS, D.A. Effects of a seed color mutation on rhizobial nod-gene-inducing flavonoids and nodulation in common bean. Molec. Plant- Microbe Inter., 6:418-422, 1993.

HUNGRIA, M.; JOSEPH, C.M. \& PHILLIPS, D.A. Anthocyanidins and favonols, major nod gene inducers from seeds of a black-seeded common bean (Phaseolus vulgaris L.). Plant Physiol., 97:751-758, 1991.

MINAMISAWA, K.; ONODERA, S. \& TANIMURA, Y. Preferential nodulation of Glycine max, Glycine soja and Macroptilium atropurpureum by two Bradyrhizobium species japonicum and elkanii. FEMS Microbiol. Ecol., 24:49-56, 1997.

NEVES, M.C.P. \& RUMJANEK, N.G. Bioquímica e fisiologia da fixação de nitrogênio. In: CARDOSO, E.J.B.N.; TSAI, S.M. \& NEVES, M.C.P., eds. Microbiologia do solo. Campinas, Sociedade Brasileira de Ciência do Solo, 1992. p.141-155.

ORGAMBIDE, G.G.; LEE, J.I.; HOLLINGSWORTH, R.I. \& DAZZO, F.B. Structurally diverse chitolipooligosaccharide Nod factors accumulate primarily in membranes of wildtype Rhizobium leguminosarum biovar trifolii. Biochemistry, 34:3832-3840, 1995.

PERES, J.R.R. Seleção de estirpes de Rhizobium japonicum e competitividade por sítios de infecção nodular em cultivares de soja (Glycine max L. Merrill). Porto Alegre, Universidade Federal do Rio Grande do Sul, 1979. 81p. (Tese de Mestrado)
PERES, J.R.R.; MENDES, I.C.; SUHET, A.R.; \& VARGAS, M.A.T. Eficiência e competitividade de estirpes de rizóbio para soja em solos de cerrado. R. Bras. Ci. Solo, 17:357-363, 1993.

PERRET, X.; STAEHELIN, C. \& BROUGHTON, W.J. Molecular basis of symbiotic promiscuity. Microbiol. Molec. Biol. Rev., 64:180-201, 2000.

POUPOT, R.; MARTINEZ-ROMERO, E. \& PROMÉ, J.C. Nodulation factors from Rhizobium tropici are sulfated or non-sulfated chitopentasaccharides containing an Nmethyl-N-acylglucosamine terminus. Biochemistry, 32:10430-10435, 1993

PUEPPKE, S.G.; BOLANOS-VÁSQUEZ, M.C.; WERNER, D.; BEC-FERTÉ, M-P.; PROMÉ, J.C. \& KRISHNAN, H.B. Release of flavonoids by soybeans cultivars McClall and Peking and their perception as signals by nitrogen-fixing symbiont Sinorhizobium fredii. Plant Physiol., 117:599-608, 1998.

SÁ, E.L.S. Diversidade fenotípica e genética de rizóbios isolados de feijoeiro (Phaseolus vulgaris) em solos ácidos de Cunha - SP. Piracicaba, Universidade de São Paulo, 2001. 109 p. (Tese de Doutorado)

SINGLETON, P.W.; BOHLOOL, B.B. \& NAKAO, P.L. Legume response to rhizobial inoculation in the tropics: Myths and realities. In: LAL, R. \& SANCHEZ, P.A., eds. Myths and science of soils of the tropics. Madison, Soil Science Society of America, 1992. p.135-155.

STACEY, G.L.S.; SANJUAN, J.; BANFALVI, Z.; NIEUWKOOP, A.J.; CHUN. J.Y.; FORSBERG, L.S. \& CARLSON, R.W. nodZ, a unique host-specific nodulation gene, is involved in the fucosylation of the lipopolysaccharide nodulation signal of Bradyrhizobium japonicum. J. Bacteriol., 176:620-633, 1994

VARGAS, M.A.T. \& HUNGRIA, M. Fixação biológica do nitrogênio na cultura da soja. In: VARGAS, M.A.T. \& HUNGRIA, M., eds. Biologia dos solos dos Cerrados. Planaltina, Embrapa-CPAC, 1997. p.297-360.

VARGAS, M.A.T. \& SUHET, A.R. Eficiência de inoculantes comerciais e de estirpes de Rhizobium para seis leguminosas forrageiras em um solo de Cerrado. Pesq. Agropec. Bras., 16:357-362, 1981. 